\title{
Studying the Effect of Some Surfactants on Drag Reduction of Crude Oil Flow
}

\author{
Ali A. Abdul-Hadi ${ }^{1}$ and Anees A. Khadom ${ }^{2}$ \\ ${ }^{1}$ Chemical Engineering Department, College of Engineering, University of Baghdad, Al Jadriya, Baghdad, Iraq \\ ${ }^{2}$ Chemical Engineering Department, College of Engineering, University of Diyala, Baquba 32001, Daiyla, Iraq \\ Correspondence should be addressed to Anees A. Khadom; aneesdr@gmail.com
}

Received 10 July 2013; Accepted 4 September 2013

Academic Editors: G. Chen, B. Ma, and C. Pham-Huu

Copyright (c) 2013 A. A. Abdul-Hadi and A. A. Khadom. This is an open access article distributed under the Creative Commons Attribution License, which permits unrestricted use, distribution, and reproduction in any medium, provided the original work is properly cited.

\begin{abstract}
The influence of SDBS, SLS, SLES, and SS as drag reducing agents on flow of Iraqi crude oil in pipelines was investigated in the present work. The effect of additive type, additive concentration, pipe diameter, solution flow rate, and the presence of elbows on the percentage of drag reduction (\%Dr) and the amount of flow increases $(\% \mathrm{FI})$ was addressed. The maximum drag reduction was $55 \%$ obtained at $250 \mathrm{ppm}$ SDBS surfactant flowing in straight pipes of $0.0508 \mathrm{~m}$ I.D. The dimensional analysis was used for grouping the significant quantities into dimensionless groups to reduce the number of variables. The results showed good agreement between the observed drag reduction percent values and the predicted ones with high value of the correlation coefficient.
\end{abstract}

\section{Introduction}

Drag reduction is a phenomenon in which the friction of a liquid flowing in a pipe in turbulent flow is decreased by using a small amount of an additive. The used drag reducing additives are effective because they reduced the turbulent friction of the solution. This resulted in a decrease in the pressure drop across a length of the pipe and likewise reduced the energy required to transport the liquid [1]. Surfactants are one of the most important drag reducing agents, which have the ability to form a certain structure called micelles. The important aspect of surfactant which impacts their performance is their ability to self-repair. This is the ability of a group of molecules to return to its original form after their structure has been altered as a result of high shear; this property recognizes the surfactant from polymers and aluminum disoaps, which degrade when subjected to high shear and generally cannot reform. Therefore, they cannot be effective in recirculating the fluid, and these pumps apply high shear stress to fluid. This causes the polymer chains to break into small segments which do not have the ability to revert to their original form. On the other hand, surfactants are able to repair themselves in a matter of seconds upon degradation of shear. This characteristic makes surfactants a good candidate for recirculation systems [2]. The mechanisms by which these agents work (turbulent suppression; extension of laminar behavior to abnormally high Reynolds numbers; or wall layer modification, reduction of friction in fully developed turbulence) are not defectively established, but they are believed to inhibit the formation of microscopic eddies in the liquid [3]. The goal of the present work was to investigate the validity of the effectiveness of SDBS, SLS, SLES and SS (concentrations of 50,100, 150, 200, and $250 \mathrm{ppm}$ ) as drag reducing agents with Kirkuk crude oil. Also to study the effect of additive type, additive concentration, pipe diameter, solution flow rate, and the presence of radius elbows on the percentage of drag reduction (\%Dr) and the amount of flow increases $(\% \mathrm{FI})$, these parameters have the most significant effect on the flow of fluids.

\section{Mechanism of Drag Reduction}

The flow in most crude oil pipelines is turbulent. This means that most of the drag, or energy loss while pumping, is due to turbulent eddies in the oil rather than the friction from pipeline walls. Drag reduction agents are chemicals that are injected into a crude oil pipeline to reduce the energy loss; this produces a solution in pressure drop smaller than that 
TABLE 1: Specification of surfactants.

\begin{tabular}{lccc}
\hline Surfactants & Scientific name & Chemical structure & Molecular weight \\
\hline SDBS & Sodium dodecyl-benzene sulfonate & $\mathrm{C}_{12} \mathrm{H}_{25} \mathrm{C}_{6} \mathrm{H}_{4} \mathrm{SO}_{3}-\mathrm{Na}$ & 348 \\
SLS & Sodium lauryl sulfate & $\mathrm{C}_{12} \mathrm{H}_{26} \mathrm{O}_{4} \mathrm{~S}-\mathrm{Na}$ & 289 \\
SLES & Sodium laureth Sulfate & $\mathrm{CH}_{3}\left(\mathrm{CH}_{2}\right)_{10} \mathrm{CH}_{2}\left(\mathrm{OCH}_{2} \mathrm{CH}_{2}\right)_{3} \mathrm{OSO}_{3}-\mathrm{Na}$ & 372 \\
SS & Sodium stearate & $\mathrm{C}_{17} \mathrm{H}_{35} \mathrm{COO}-\mathrm{Na}$ & 306 \\
\hline
\end{tabular}

TABLE 2: Relative roughness and length of pipes used.

\begin{tabular}{lccc}
\hline Pipe inside diameter, $\mathrm{m}$ & Relative roughness, $\varepsilon / d$ & Length of pipe with elbows, $\mathrm{m}$ & Length of straight pipe, $\mathrm{m}$ \\
\hline 0.0508 & 0.000885 & 4.656 & 3 \\
0.0254 & 0.001770 & 2.378 & 3 \\
0.0191 & 0.002362 & 1.687 & 3 \\
\hline
\end{tabular}

which would occur with untreated solvent moving at the same flow rate. Drag reduction agents are described as a thick, viscous liquid with the appearance of old honey and highly viscoelastic. DRAs used in oil and products pipelines are themselves hydrocarbons and thus should have no effect on physical properties of refining processes or refined products. DRA-solvent solutions are viscoelastic, time-independent, shear degradable, and non-Newtonian fluids [4, 5]. Several types of additives cause drag reducing phenomena to occur. Surfactants are the focus of this research because they were used as a drag reduction agent. The surfactants of different types anionic, nonionic, Zwitterionic, and cationic behave in a characteristic manner in solutions. In these solutions, the hydrophobic group avoids contact with polar molecules by forming micelles. In micelles, the hydrophilic parts, which are polar, contact the polar molecules allowing the nonpolar, hydrophobic parts to concentrate in the center of the micelle. Surfactants as well as the structure of the micelle both contribute to the high drag reducing properties of the molecule. An important aspect of drag reducing surfactant additives which impacts their performance is their ability to self-repair. This is the ability of a group of molecules to return to their original form after its structure has been altered as a result of high shear [6].

\section{Experimental Work}

3.1. Liquids. Kirkuk crude oil (Kirkuk governorate, Iraq) which was used in the present work (provided from AlDura refinery, Iraq). The physical properties of this crude oil were 2.296 viscosity @ $25^{\circ} \mathrm{C}$ (c.st), 0.8513 specific gravity, and 35.40 API. The kinematic viscosity of Iraqi crude oil was calculated according to ASTM D-445, while specific gravity was according to ASTM D 1217-81.

3.2. Surfactants. SDBS, SLS, SLES, and SS are anionic surfactants which were used as a drag reducing agents (concentrations $50,100,150,200$, and $250 \mathrm{ppm}$ ) in the present work. They were supplied by General Company of Vegetable Oil Industries, Baghdad, Iraq. The specifications and some physical properties are shown in Table 1.

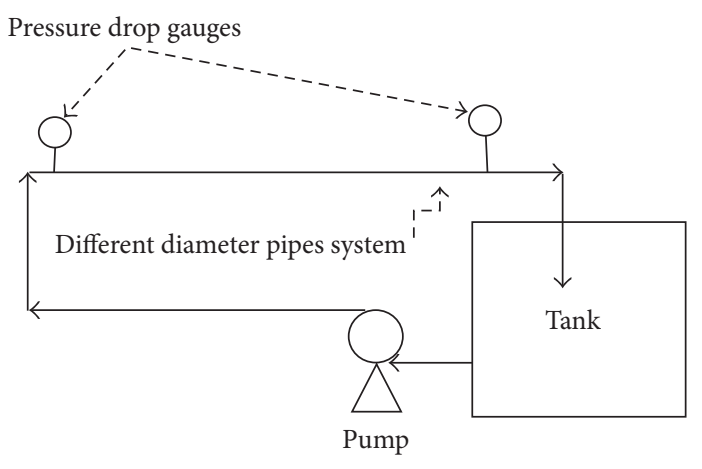

FIGURE 1: Schematic diagram of flow system.

3.3. Description of Circulating Flow Loop System. Figure 1 represents the schematic diagram of flow system apparatus used in the present work, which consists of reservoir tank of solution $\left(0.88 \times 0.88 \times 0.88 \mathrm{~m}^{3}\right.$ volume $)$, centrifugal pumps (flow rate $=45 \mathrm{~m}^{3} / \mathrm{hr}$; Power $=25 \mathrm{hp}$ ) which was used to circulate the solution from the reservoir tank through pipes, while another pump (flow rate $=1 \mathrm{~m}^{3} / \mathrm{hr}$; Power $=0.5 \mathrm{hp}$ ) was connected to the draining exit of the tank, flow meter ( $12 \mathrm{~m}^{3} / \mathrm{h}$ maximum flow rate), valves to control the amount and direction of solution flow rate through the system, pressure gauges, and pipes of different inside diameters (0.0508, 0.0254 , and $0.0191 \mathrm{~m}$ ). These pipes are made of commercial carbon steel with relative roughness shown in Table 2.

3.4. Experimental Procedure. The preparation of additive solution by mixing small amounts of surfactants with a sample of crude oil is the first step in the experimental procedure; then the solution is added into the reservoir tank of crude oil to use in the recirculation closed system. The operation is started by pumping the solution through the testing section for the same pipe diameter, additive type, and additive concentration. For each run, the flow rate of the solution was controlled bypass section to a certain value, while pressure drop readings were taken. Readings of pressure drop were taken again when the flow rate of the solution was changed to another fixed value. This procedure 
TABLE 3: Experimental data for 150 ppm SLES surfactant dissolved in the Kirkuk crude oil flowing in $0.0254 \mathrm{~m}$ I.D. pipe.

\begin{tabular}{lcccc}
\hline $\mathrm{Q}\left(\mathrm{m}^{3} / \mathrm{hr}\right)$ & $\mathrm{Re}$ & $\% \mathrm{Dr}_{1}$ & $f_{1}$ & $\% \mathrm{FI}_{1}$ \\
\hline 1 & 6064.57 & 17.34 & 0.007561 & 11.04 \\
2 & 12129.14 & 18.25 & 0.006937 & 11.72 \\
3 & 18193.70 & 19.44 & 0.006572 & 12.62 \\
4 & 24258.27 & 20.22 & 0.005930 & 13.23 \\
5 & 30322.84 & 21.18 & 0.005966 & 13.99 \\
6 & 36387.41 & 22.61 & 0.005308 & 15.14 \\
7 & 42451.97 & 24.30 & 0.004962 & 16.55 \\
8 & 48516.54 & 25.33 & 0.004764 & 17.43 \\
9 & 54581.11 & 26.31 & 0.004383 & 18.28 \\
10 & 60645.68 & 28.31 & 0.004115 & 20.09 \\
11 & 66710.25 & 28.67 & 0.003980 & 20.42 \\
12 & 72774.81 & 30.43 & 0.003658 & 22.09 \\
\hline
\end{tabular}

was repeated for each pipe diameter, additive type, additive concentration, and crudes type.

\section{Results and Discussion}

4.1. Results Calculations. Four anionic surfactant types (SDBS, SLS, SLES, and SS) as drag reducing agents with Iraqi crude oil (Kirkuk crude oil) were used. The Factorial experimental design was used. The following equations were used to calculate the Reynolds number (Re), percentage drag reduction (\%Dr), percentage flow increase (\%FI) [7], and friction factor in terms of fanning friction factor [8], respectively:

$$
\begin{aligned}
\operatorname{Re} & =\frac{\rho \cdot v \cdot d}{\mu}, \\
\% \mathrm{Dr} & =\frac{\Delta P_{b}-\Delta P_{a}}{\Delta P_{b}}, \\
\% \mathrm{FI} & =\left(\frac{1}{1-(\% \mathrm{Dr} / 100)^{0.55}}-1\right) \times 100, \\
f & =\frac{\Delta P \cdot d / 4 L}{\rho \cdot v^{2} / 2},
\end{aligned}
$$

where $\rho$ is the density, $v$ is the linear velocity, $d$ is the pipe diameter, $\mu$ is the viscosity, $\Delta P_{b}$ and $\Delta P_{a}$ are the pressure drop before and after addition of surfactants, and $L$ is the pipe length. Table 3 shows the experimental calculation. Similar tables were obtained for other surfactants at different conditions. Table 3 shows the maximum values of $\% \mathrm{Dr}\left(\% \mathrm{Dr}_{1}\right.$ in pipe with elbows, $\% \mathrm{Dr}_{2}$ in straight pipelines) and $\% \mathrm{FI}$ for all drag reducing agents with Kirkuk crude oil solution. Maximum $\% \mathrm{Dr}_{2}$ of $55 \%, 42 \%$, and $30 \%$ were obtained using Kirkuk crude oil containing $250 \mathrm{ppm}$ of SDBS surfactant flowing in straight pipes of 5.08, 2.54, and $1.91 \mathrm{~cm} \mathrm{I.D.,}$ respectively. While the maximum $\% \mathrm{Dr}_{1}$ of $48 \%, 45 \%$, and $32 \%$ were obtained using Kirkuk crude oil flowing in the pipes of different lengths (i.e., $1.1 \mathrm{~m}$ for $5.08 \mathrm{~cm}$ I.D., $0.6 \mathrm{~m}$ for $2.54 \mathrm{~cm}$ I.D., and $0.35 \mathrm{~m}$ for $1.91 \mathrm{~cm}$ I.D.), each joined with

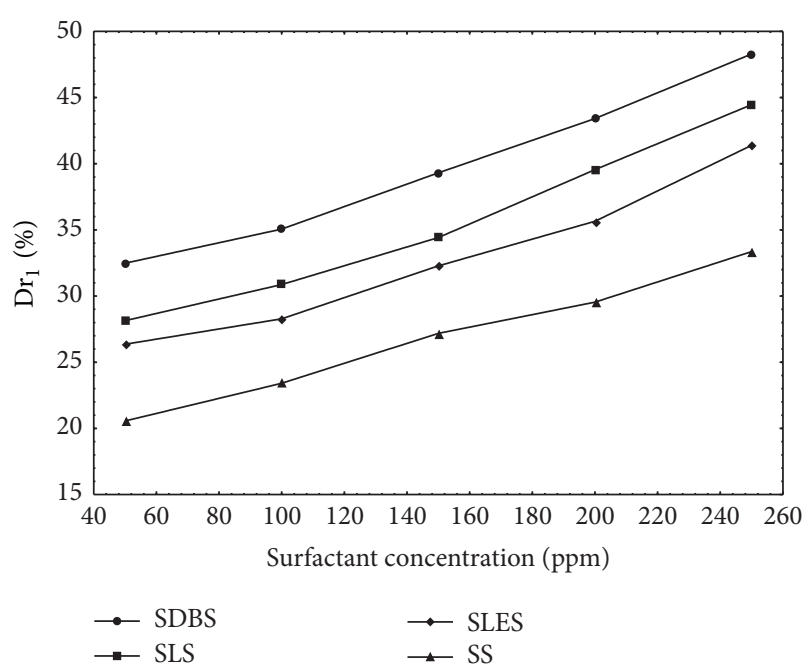

FIGURE 2: The effect of surfactant concentration on drag reduction for $0.0508 \mathrm{~m}$ pipe diameter and $12 \mathrm{~m}^{3} / \mathrm{h}$ flow rate.

two elbows of standard radius. The SDBS has a large stability than other additives. This may be attributed to the structure of micelles formed in the surfactant solution and its resistance to the shear forces which governs the effectiveness of the surfactant used as drag reducer. The order of reduction was as follows:

$$
\text { SDBS }>\text { SLS }>\text { SLES }>\text { SS. }
$$

4.2. Effect of Surfactant Concentration. Figure 2 shows the effect of surfactant concentration on drag reduction process. The same figures can be obtained at different conditions. These figures show that the \%Dr increases with increasing the additive concentration. The increment in $\% \mathrm{Dr}$ is ascribed to increases of associated additive molecules in the process of drag reduction. Also, it shows that there is no limited value of concentration after which no further drag reduction occurs within additives concentration (50-250 ppm) for surfactants. In order to check that the additives do not affect the physical properties of used crude oil, the viscosity of crude oil was evaluated; the results indicate that there is no change in physical properties after addition. These results agree with the work of Takashi and Hiromoto [9] and others [10].

4.3. Effect of Pipe Diameter. Figure 3 shows the effect of pipe diameter on $\%$ Dr. The comparison of $\%$ Dr between the three pipes achieved at a constant flow rate through each of them, certain additive type, and concentration. The results show that $\%$ Dr increase with pipe diameter increasing within certain additive type and concentration. This increase in $\% \mathrm{Dr}$ is attributed to large eddies that exist in the pipe of large diameter, which absorb large amount of energy from the main flow. While in the small pipes, the number of formed small eddies were larger than large eddies formed in the large pipes. These small eddies needed a large amount of energy absorbed from the main flow to overcome the resistance of viscosity and then complete its shape. Not all small eddies 


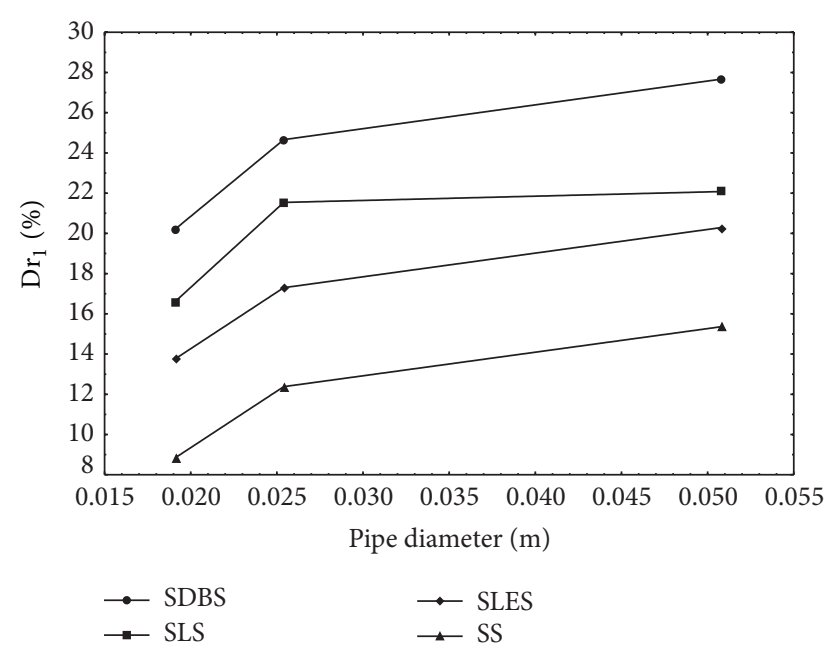

FIGURE 3: Effect of pipe diameter on drag reduction for $50 \mathrm{ppm}$ surfactant concentration and $6 \mathrm{~m}^{3} / \mathrm{h}$ flow rate.

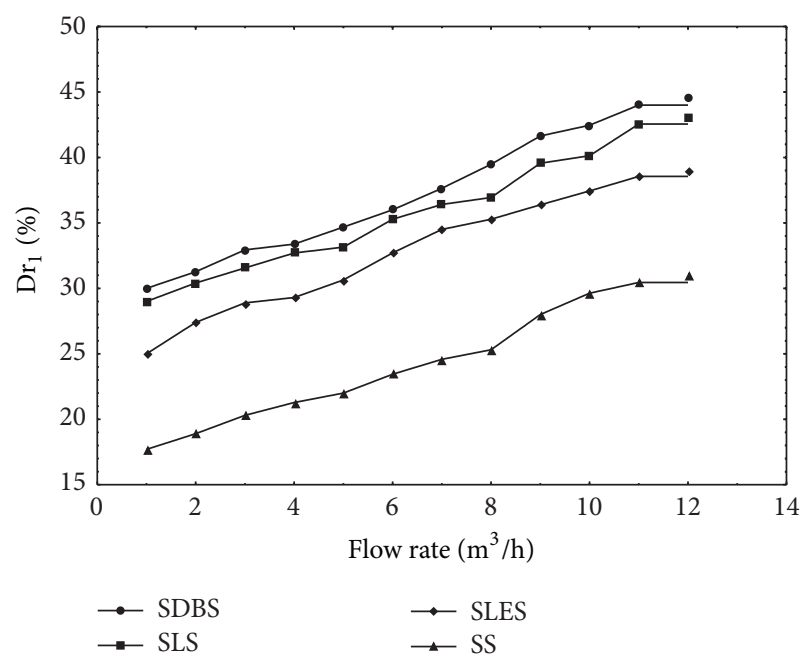

FIgURE 4: Effect of flow rate on drag reduction for different surfactants at $250 \mathrm{ppm}$ concentration flowing in $0.0254 \mathrm{~m}$ I.D. pipe.

absorb equal amount of energy, some of them absorb amount of energy not that is able to overcome viscous resistance and then eventually disappear causing loss in the energy of the main flow, while the other eddies absorb enough energy and enable to overcome viscosity resistance. The \%Dr in small pipes is lower than in large pipes due to small eddies which absorb small amount of energy that does not enable it to overcome viscosity resistance [11].

4.4. Effect of Flow Rate. Figure 4 shows the effect of solution velocity $(v)$ on the percentage drag reduction (\%Dr) in terms of dimensionless group (Re). The results show that the drag reduction percentage increases with increasing fluid velocity. Increasing the fluid velocity means increasing the degree of turbulence inside the pipe, this will provide a better media to the drag reducer to be more effective. The behavior of increasing \% Dr with velocity of fluid may be explained due

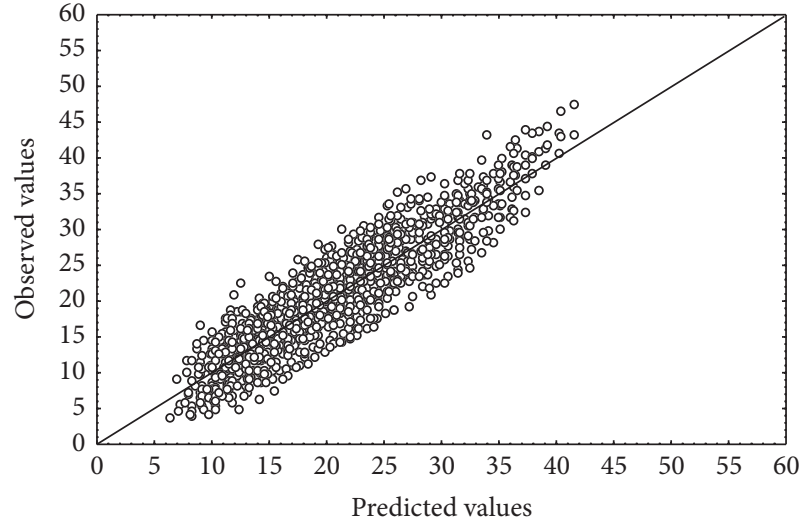

FIGURE 5: Predicted versus observed values of drag reduction for crude oil flowing through pipes.

to relation between degree of turbulence controlled by the solution velocity and the additive effectiveness. The same results were obtained by Kim et al. [12]; the drag reduction was larger at high Reynolds number.

4.5. Effect of Friction. Figure 5 showed that the friction factor for various Re, pipe diameter, additives type, and additives concentrations is shown. These figures are divided into four regions. These regions are as follows [13].

(1) Laminar flow region $(\operatorname{Re}<2300)$, where the friction factor follows Poisuell's law as follow:

$$
f=16 \mathrm{Re}^{-1} \text {. }
$$

(2) Transition region $(\mathrm{Re}=2300-3000)$, where the flow change from laminar to turbulent flow. Friction coefficient rises rapidly.

(3) Turbulent region $(\operatorname{Re}>3000)$, where the friction factor follow Blasius law:

$$
f=0.0791 \mathrm{Re}^{-0.25} \text {. }
$$

(4) Virk asymptote region, which is suggested by Virk to represent the greatest possible fall in resistance in which the relation between friction factor $(f)$ and Re does not depend on the nature of the additives or pipe diameter. The formula for Virk is

$$
f=0.59 \mathrm{Re}^{-0.58} .
$$

These figures showed that the friction factor decreased with decreasing the pipe diameter, with increasing concentration of additives, and with increasing fluid velocity. From these figures, it can be noticed that most of experimental data points are located at or close to Blasius asymptote when the solvent was pure. After the addition of additives, the data points positioned toward Virk asymptote which represent the maximum limits of drag reduction (Table 4). It was difficult to reach these limits of lowering resistance because the higher concentration of additives are required to achieve this condition. But it must be taken into account that higher concentration should not affect solvent properties. 
TABLE 4: Maximum values of $\% \mathrm{Dr}$ and $\% \mathrm{FI}$ at $250 \mathrm{ppm}$ concentration surfactant.

\begin{tabular}{|c|c|c|c|c|c|c|}
\hline Additive type & Pipe diameter $(\mathrm{m})$ & Flow rate $\left(\mathrm{m}^{3} / \mathrm{hr}\right)$ & Max. $\% \mathrm{Dr}_{1}$ & Max. $\% \mathrm{Dr}_{2}$ & Max. $\% \mathrm{FI}_{1}$ & Max. $\% \mathrm{FI}_{2}$ \\
\hline SDBS & 0.0508 & 12.00 & 48.29 & 54.48 & 43.73 & 54.17 \\
\hline SLS & 0.0508 & 12.00 & 44.46 & 47.30 & 38.19 & 42.23 \\
\hline SLES & 0.0508 & 12.00 & 41.39 & 43.00 & 34.16 & 36.23 \\
\hline SS & 0.0508 & 12.00 & 33.36 & 35.34 & 25.01 & 27.10 \\
\hline SDBS & 0.0254 & 12.00 & 45.31 & 42.54 & 39.36 & 35.63 \\
\hline SLS & 0.0254 & 12.00 & 42.48 & 40.51 & 35.55 & 33.06 \\
\hline SLES & 0.0254 & 12.00 & 38.40 & 36.98 & 30.54 & 28.91 \\
\hline SS & 0.0254 & 12.00 & 32.00 & 28.80 & 23.63 & 20.54 \\
\hline SDBS & 0.0191 & 6.00 & 31.50 & 29.86 & 23.13 & 21.54 \\
\hline SLS & 0.0191 & 6.00 & 27.40 & 26.58 & 19.26 & 18.52 \\
\hline SLES & 0.0191 & 6.00 & 25.70 & 24.87 & 17.75 & 17.03 \\
\hline SS & 0.0191 & 6.00 & 21.37 & 20.00 & 14.14 & 13.06 \\
\hline
\end{tabular}

4.6. Correlation of Variables. The dimensional analysis was used in the present work for grouping the significant quantities into a dimensionless group to reduce the number of variables appearing and to make the result so compact and applicable to all similar situations. The drag reduction is influenced by the physical properties of solvent and properties of flow. The relationship may be written as

$$
\Delta P=f(D, \mu, \rho, V, C, L, \varepsilon) .
$$

By applying the dimensional analysis, the following nondimensional relation was proposed:

$$
\% \mathrm{Dr}=f\left(\operatorname{Re}, \frac{\varepsilon}{d}, \frac{L}{d}, C\right)
$$

or

$$
\% \mathrm{Dr}=a(\operatorname{Re})^{b}\left(\frac{\varepsilon}{d}\right)^{c}\left(\frac{L}{d}\right)^{d}(C)^{k} .
$$

The method of least square was used to determine the coefficients of correlation for Reynolds number range (434172775). The coefficients for this system (i.e., for pipes diameter, additives type, and solvents type) were summarized in the following with 0.9032 correlation coefficient:

$$
\% \text { Dr }=0.134(\mathrm{Re})^{0.324}\left(\frac{\varepsilon}{d}\right)^{-0.806}\left(\frac{L}{d}\right)^{-0.934}(C)^{0.153} \text {. }
$$

\section{Conclusion}

The additives (SDBS, SLS, SLES, and SS) were found to be effective drag reducing agent when used with Kirkuk crude oil. Drag reduction percent or flow increase percent are increased as the velocity of solution increased. Drag reduction percent is increased with increasing concentration of additives. It is observed that the additives do not affect the physical properties of used crude oils. A correlation equation was obtained to represent the experimental data mathematically using least square method in analysis. This correlation showed the drag reduction percent $(\% \mathrm{Dr})$ as a function of Reynolds number (Re), concentration of additives
$(C)$, roughness factor $(\varepsilon / d)$, and the ratio $(L / d)$. The results showed good agreement between the observed drag reduction percent values and the predicted ones with high value of correlation coefficients.

\section{Acknowledgment}

This work was supported by Baghdad University, Chemical Engineering Department, which is gratefully acknowledged.

\section{References}

[1] F.-C. Li, Y. Kawaguchi, B. Yu, J.-J. Wei, and K. Hishida, "Experimental study of drag-reduction mechanism for a dilute surfactant solution flow," International Journal of Heat and Mass Transfer, vol. 51, no. 3-4, pp. 835-843, 2008.

[2] K. Prajapati, Interactions between drag reducing polymers and surfactants [M.S. thesis], University of Waterloo, Ontario, Canada, 2009.

[3] H. Ferhat and G. Sylvain, "Drag reduction by surfactant in closed turbulent flow," International Journal of Engineering Science and Technology, vol. 2, pp. 6876-6879, 2010.

[4] C. B. Lester, "Drag reduction agents," Oil and Gas Journal, vol. 4, pp. 51-56, 1985.

[5] R. Martínez-Palou, M. D. L. Mosqueira, B. Zapata-Rendón et al., "Transportation of heavy and extra-heavy crude oil by pipeline: a review," Journal of Petroleum Science and Engineering, vol. 75, no. 3-4, pp. 274-282, 2011.

[6] J. Zakin, "Surfactant drag reduction," Reviews in Chemical Engineering, vol. 1, pp. 252-320, 1998.

[7] R. Darby, Engineering Fluid Mechanics, Marcel Dekker, New York, NY, USA, 2nd edition, 2001.

[8] F. A. Holland and R. Bragg, Fluid Flow for Chemical Engineers, Edward Arnold, London, UK, 2nd edition, 1995.

[9] S. Takashi and U. Hiromoto, "Drag reduction and heat transfer reduction by cationic surfactants," Journal of Chemical Engineering of Japan, vol. 26, no. 1, pp. 103-106, 1993.

[10] D. Mowla and A. Naderi, "Experimental study of drag reduction by a polymeric additive in slug two-phase flow of crude oil and air in horizontal pipes," Chemical Engineering Science, vol. 61, no. 5, pp. 1549-1554, 2006. 
[11] H. R. Karami and D. Mowla, "Investigation of the effects of various parameters on pressure drop reduction in crude oil pipelines by drag reducing agents," Journal of Non-Newtonian Fluid Mechanics, vol. 177-178, pp. 37-45, 2012.

[12] N.-J. Kim, J.-Y. Lee, S.-M. Yoon, C.-B. Kim, and B.-K. Hur, "Drag reduction rates and degradation effects in synthetic polymer solution with surfactant additives," Journal of Industrial and Engineering Chemistry, vol. 6, no. 6, pp. 412-418, 2000.

[13] S. N. Ashrafizadeh, E. Motaee, and V. Hoshyargar, "Emulsification of heavy crude oil in water by natural surfactants," Journal of Petroleum Science and Engineering, vol. 86, pp. 137-143, 2012. 

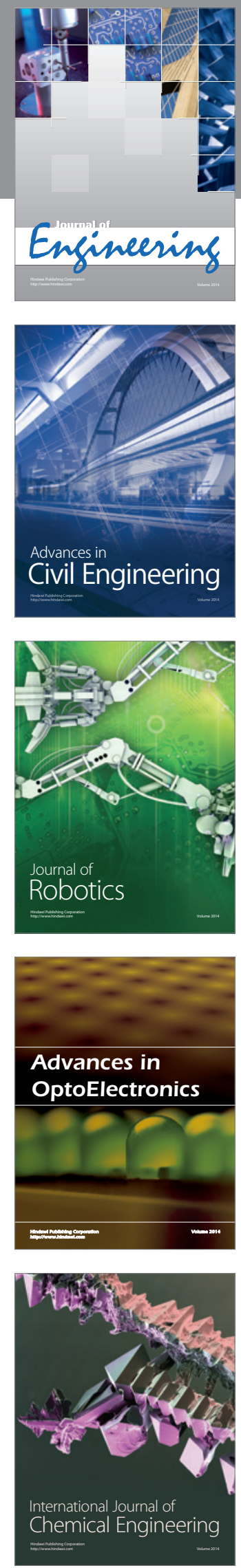

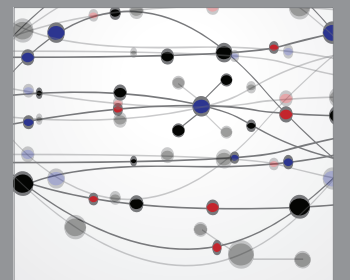

The Scientific World Journal
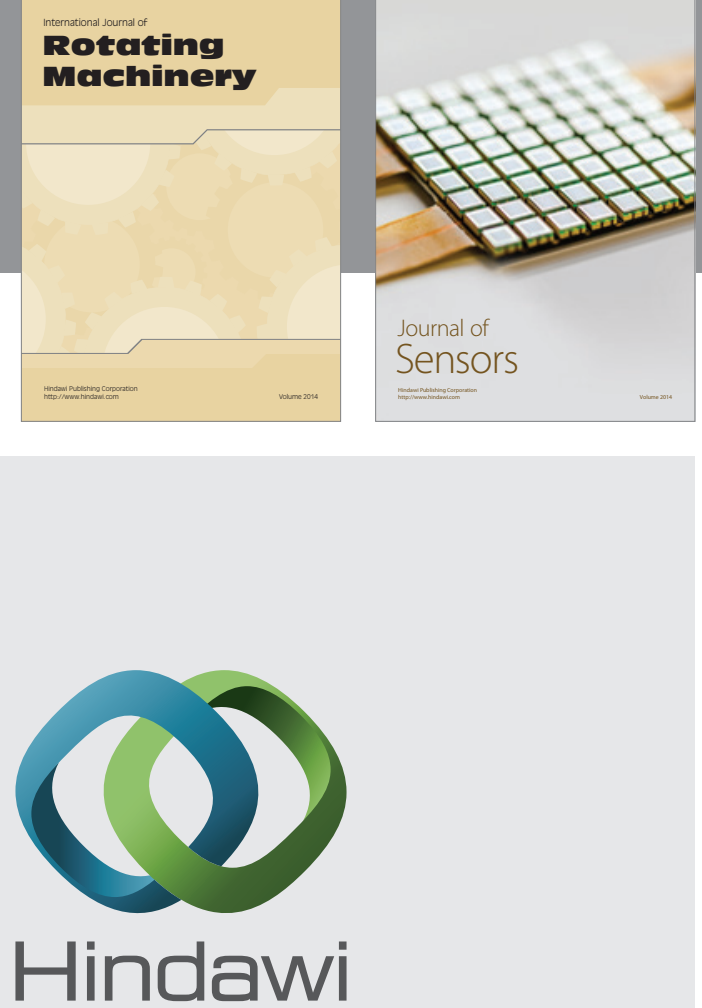

Submit your manuscripts at http://www.hindawi.com
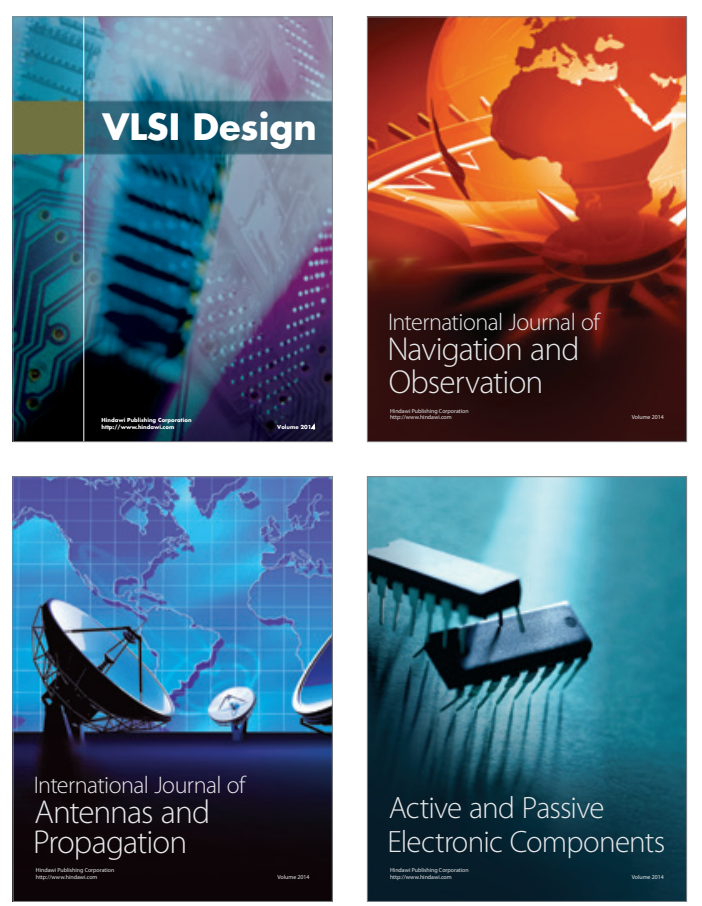
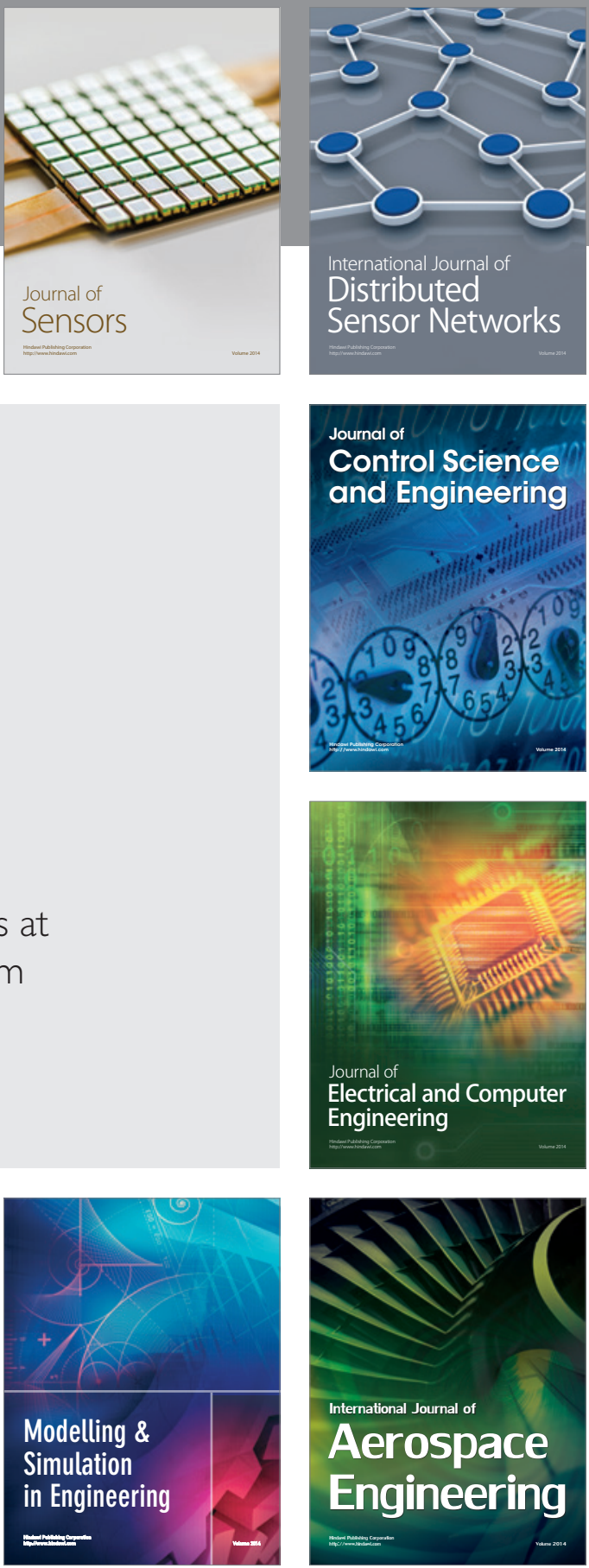

Journal of

Control Science

and Engineering
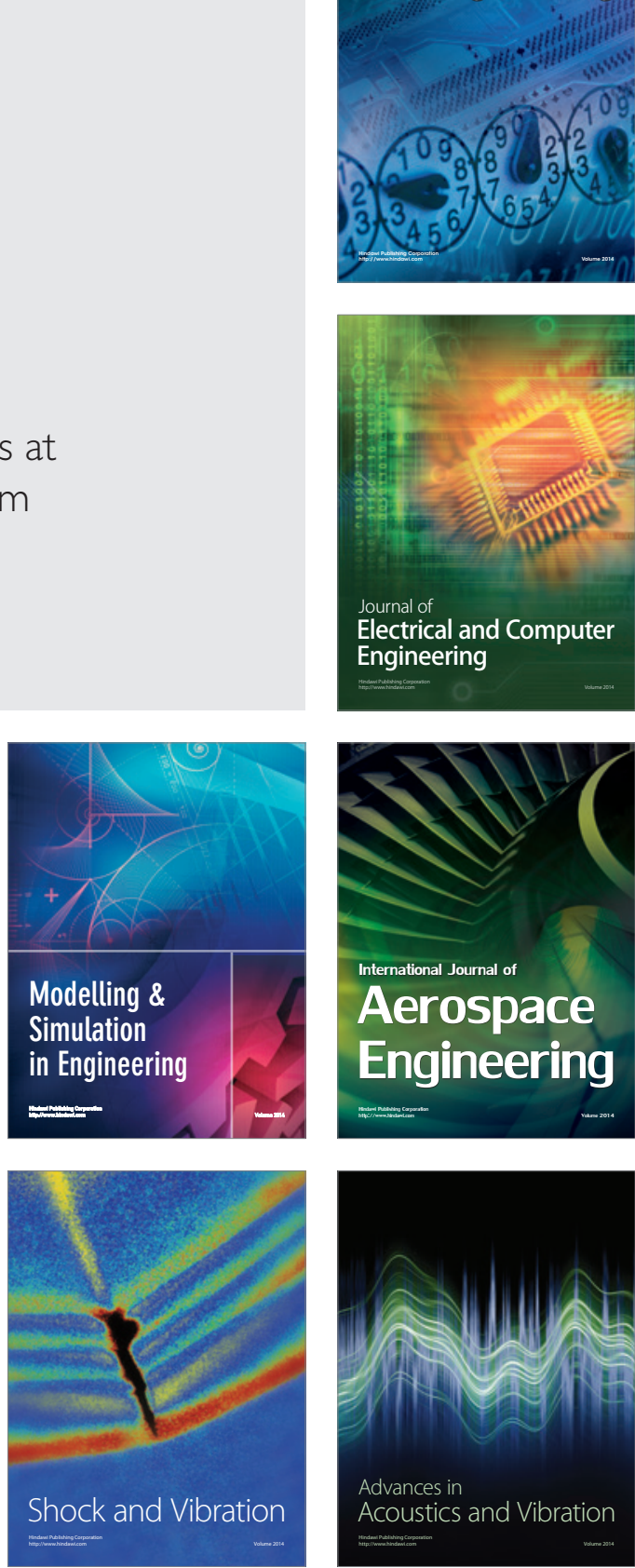